\title{
1 A framework to assess evolutionary responses to anthropogenic light and sound
}

2

3 John Swaddle*, College of William and Mary

4 Clinton D. Francis*, California Polytechnic State University, San Luis Obispo

5 Jesse R. Barber, Boise State University

6 Caren B. Cooper, Cornell Lab of Ornithology

7 Christopher C.M. Kyba, Deutsches GeoForschungsZentrum Potsdam and Leibniz-Institute of

8 Freshwater Ecology and Inland Fisheries

9 Davide Dominoni, University of Glasgow

10 Graeme Shannon, Colorado State University

11 Erik Aschehoug, North Carolina State University

12 Sarah E. Goodwin, University of Massachusetts-Amherst

13 Akito Y. Kawahara, University of Florida

14 David Luther, George Mason University

15 Kamiel Spoelstra, Netherlands Institute of Ecology

16 Margaret Voss, Syracuse University

17 Travis Longcore, University of Southern California and The Urban Wildlands Group

$19 *$ denotes joint first authorship

20

21

22 


\section{Keywords}

25 Light at night; anthropogenic noise; signalling; circadian rhythms; phenology; masking

\section{Abstract}

29 Human activities have caused a near-ubiquitous and evolutionarily-unprecedented increase in

30 environmental sound levels and artificial night lighting. These stimuli reorganize communities

31 by interfering with species-specific perception of time cues, habitat features, and auditory and

32 visual signals. Rapid evolutionary changes could occur in response to light and noise, given their

33 magnitude, geographical extent, and degree to which they represent unprecedented

34 environmental conditions. We present a framework for investigating anthropogenic light and

35 noise as agents of selection, and as drivers of other evolutionary processes, to influence a range

36 of behavioural and physiological traits, such as phenological characters and sensory and

37 signalling systems. In this context, opportunities abound for understanding contemporary and

38 rapid evolution in response to human-caused environmental change. 


\section{Global changes in distribution of anthropogenic light and sound}

46 Worldwide human population growth dramatically influences organisms through urbanization,

47 industrialization, and transportation infrastructure [1]. The environmental disruption associated

48 with the exponential increase in human populations has led to extinction, altered community

49 structure, and degraded ecosystem function [1]. Pollution is among the key aspects of human-

50 induced rapid environmental change. Anthropogenic noise and artificial light are sensory

51 pollutants that have increased over recent decades, and pose a global environmental challenge in

52 terrestrial [2] and aquatic environments [3]. In 2001 approximately $40 \%$ of the world population

53 lived in areas that never experienced sub-moonlight illuminance [4]. Baseline night light levels

54 are increased by skyglow, artificial light scattered by the atmosphere back towards the ground.

55 The overcast night sky radiance in urban areas has been found to be as much as four orders of

56 magnitude larger than in natural settings (Figure 1)[5]. Similarly, increased noise levels affect a

57 sizable proportion of the human population. In Europe for instance, $65 \%$ of the population is

58 exposed to ambient sound levels exceeding $55 \mathrm{~dB}(\mathrm{~A})$ [6], roughly equivalent to constant rainfall.

59 Of the land in the contiguous U.S., $88 \%$ is estimated to experience elevated sound levels from

60 anthropogenic noise (Figure 1)[7]. These effects are not limited to terrestrial environments;

61 ocean noise levels are estimated to have increased by 12 decibels (an $\sim 16$-fold increase in sound

62 intensity) in the past few decades from commercial shipping alone [8], while an estimated $22 \%$

63 of the global coastline is exposed to artificial light [3] and many offshore coral reefs are

64 chronically exposed to artificial lighting from cities, fishing boats, and hydrocarbon extraction

$65[9]$.

66 The changes in light at night and noise levels are occurring on a global scale similar to

67 well-recognized ecological and evolutionary forces such as land cover and climate change. In 
68 parallel with research involving climate change [10], much of our understanding of organismal

69 response to noise and light is restricted to short-term behavioural reactions. Organismal

70 responses might be associated with tolerance to these stimuli in terms of habitat use [11,12], or

71 include shifts to quieter and darker areas $[13,14]$. Although organisms have responded to land

72 cover changes and climatic variability throughout history [10], the levels of night lighting and

73 noise now experienced are unprecedented in the evolutionary record. The rapid rise of these

74 novel stimuli could decrease the likelihood that organisms possess the genetic variance to adapt

75 to the altered environmental conditions.

76 Exposure to anthropogenic noise and artificial light can negatively affect the primary

77 sensory modalities by which most animals interact with their environment. Visual and auditory

78 systems mediate essential behaviours, including foraging, predator avoidance, territory defence,

79 and mating decisions [15]. When anthropogenic noise and light disrupt sensory systems, we

80 expect a cascade of effects on behaviours and associated life history traits. Light, for example,

81 plays a key role in modulating the circadian rhythms of both invertebrates and vertebrates, and

82 influences longer-term phenological responses [16]. Elevated light at night can reduce fitness

83 through immunosuppression [17] and alter reproductive physiology [18]. In terms of sound

84 stimuli, masking of acoustic cues is a mechanism by which noise affects animals [11]. This has

85 been studied in the context of songbird communication [12], yet masking can also influence

86 perceived risk due to impaired acoustic surveillance [19]. Other factors, such as distraction of an

87 animal's finite attention [17], have the potential to alter a variety of behaviours and traits.

88 Mounting evidence suggests that noise and night lighting have strong ecological

89 consequences [2,20], yet we know little about how these stimuli can drive evolutionary

90 responses. Here, we argue that evolutionary responses to these stimuli are highly likely and 
91 propose a framework to guide future research (Figure 2), particularly as current studies rarely

92 distinguish between behavioural flexibility, developmental plasticity, or heritable genetic

93 responses. We describe how observed and hypothesized responses to these stimuli by individuals

94 and populations are linked through various mechanisms to evolutionary outcomes. Specifically,

95 we use a reaction-norm approach to show how researchers can investigate light and sound-

96 derived evolutionary responses. We then discuss how known behavioural and developmental

97 responses could contribute to evolutionary change.

\section{Status of research on anthropogenic light and sound in ecology}

99 Night lighting and noise are highly correlated in many landscapes (e.g., [21]). It is critical to

100 understand whether the selective pressures these stimuli exert are additive, synergistic (Figure 2),

101 or if they mitigate one another. Few studies have examined the influence of each simultaneously

102 (e.g., [21]). In one study, flashing lights combined with boat motor noise suppressed antipredator

103 behaviour in hermit crabs (Coenobita clypeatus) more so than noise alone [22]. Future research

104 should quantify both light and sound simultaneously in the same population. Existing research

105 has largely focused on these stimuli in isolation, so we briefly summarize the research status of

106 each separately.

\section{Anthropogenic sound as a potential selection pressure}

108 Noise can alter physiology, behaviour (communication, foraging, vigilance), and population-

109 level metrics such as abundance and density [11]; limited work suggests community-level effects

110 [23]. Most studies have been conducted over short time periods, and underlying mechanisms are

111 rarely elucidated. Francis and Barber [11] proposed a framework for understanding and

112 predicting behavioural responses and the likely fitness consequences in terms of both acute and

113 chronic noise exposure. Despite these steps towards an understanding of the ecological outcomes 
114 of noise, it is unclear to what extent the documented outcomes represent evolutionary changes.

115 Similar to current challenges in understanding tolerance to climate change [10], a central

116 question is whether coping mechanisms among populations that persist in noisy environments

117 reflect behavioural flexibility, developmental plasticity, or microevolutionary responses. Some

118 recent evidence points to short-term behavioural responses [24], but it is unclear whether this

119 might be linked to microevolutionary responses that simply have not received attention (see

120 below).

\section{Anthropogenic light as a potential selection pressure}

122 The crucial role light plays in the regulation of physiology [25] and species interactions [26] has

123 been well studied, yet widespread effects of artificial light have received limited research

124 attention the past decade, starting with Longcore and Rich [27,28]. Until then, most research had

125 focused on documenting large-scale mortality events resulting from the attraction and

126 disorientation of animals (e.g., turtles and birds) by artificial lighting [28]. Research in the last

127 decade, however, have involved numerous biological responses [3,20], including effects of light

128 on physiology [17], reproduction [29], foraging [30], movement [31], communication [32], and

129 community ecology [33]. In addition to the range of biological responses, studies are now

130 beginning to consider effects from specific light spectra [34]. As with noise pollution,

131 evolutionary implications are largely understudied. One intriguing exception is a study of

132 nocturnal orb-web spiders, which demonstrated that webs were preferentially built in areas that

133 were artificially lit and, importantly, that the behaviour had a heritable basis [35].

\section{From proximate to ultimate effects of anthropogenic light and sound}

135 Organisms respond to anthropogenic light and noise, in a proximate sense, by way of two 136 mechanisms. One mechanism involves immediate adjustments to behaviour and physiology, 
137 which we define as behavioural flexibility. The other mechanism operates through alterations of

138 developmental processes and gene expression that are influenced by local environmental

139 conditions as the organism develops its phenotype; this is developmental plasticity. Both forms

140 of variation can be visualized as a reaction norm (Figure 3a), which illustrates how phenotypic

141 expression varies across a range of environments. Specifically, developmental plasticity is

142 indicated by the slope of a single reaction norm and indicates whether a particular genotype

143 varies its ontogenetic production of a phenotype across an environmental gradient. Behavioural

144 flexibility can be visualized as error bars around a particular genotype (Figure 3a). In other

145 words, a genotype (e.g., an individual organism) can vary its behaviour within a particular level

146 of the environment, but it can also change its behaviour if it experiences a shift in the

147 environment.

148 Behaviourally flexible and developmentally plastic phenotypes resulting from noise and

149 light have largely been viewed as proximate responses to novel conditions [32,36]; however,

150 environmentally-induced phenotypes can become fixed through genetic accommodation and

151 assimilation [37], thus these responses could represent an initial step towards heritable change

152 (Figure 2c). Yet behavioural flexibility could also weaken selection. If the majority of genotypes

153 adjust behaviour in an adaptive direction there will generally be a decrease in the strength of

154 selection, because many genotypes will experience relatively enhanced fitness. Considerable

155 evidence has amassed for behaviourally flexible responses to alterations of the light and sound

156 environment (reviewed above). Studies should now take the next step to understand to what

157 degree these changes are linked, and potentially drive, heritable change.

158 Adaptive developmental plasticity can increase the strength of selection [38] because

159 genotypes capable of producing the higher fitness phenotypes will be selected for more strongly 
160 than those unable to shift ontogeny in this adaptive direction. Even if most genotypes shift in an

161 adaptive direction, mechanisms of genetic accommodation could lead to positive selection [39].

162 There are few published studies involving developmentally plastic responses to noise and light

163 relative to evidence for immediate behavioural responses. Recent experiments using mice found

164 early life exposure to light at night can elevate anxiety behaviour in adulthood [40]. This is not

165 surprising given the extent to which photoperiod can impact the development of mice as a

166 function of altered circadian molecular rhythms, both during the perinatal [41] and postnatal

167 phases [42]. In birds, incubation under a long photoperiod results in smaller hatching size, a

168 fitness-related trait [43]. In terms of alteration of the acoustic environment, loud sounds can alter

169 the developmental trajectories of marine invertebrates [44], insects [36], and rodents [45].

170 Anthropogenic light and sound could also have heritable effects on developmental

171 trajectories, i.e., epigenetic effects (Figure 2c). Short-term changes in photoperiod can influence

172 gene expression profiles as well as DNA methylation, which might also be reversed by changes

173 in light regimes [46]. To our knowledge, researchers have yet to report possible epigenetic

174 influences of noise.

175 A central, yet relatively unexplored, question is whether the observed variation in a trait

176 responsive to noise or light is best explained by behavioural flexibility or developmental

177 plasticity. If developmental plasticity best explains the variation observed in nature, then it

178 increases opportunities for populations to respond in evolutionary ways. To assess this

179 evolutionary potential, information about the heritability of focal response traits must be

180 collected in the field as the environment is changing (Box 1). Understanding the heritability of

181 traits and the intensity and direction of selection as they occur in the field would allow prediction

182 of evolutionary outcomes for populations as well as understanding of current levels of 
183 adaptation. Such research must address the complexities of selecting appropriate measurement

184 techniques, equipment, measurement precision, and units for characterization of light and sound 185 environments (Box 2).

\section{Potential microevolutionary responses}

188 Adaptive responses to anthropogenic light and sound require 1) a heritable response in the

189 population (e.g., mating calls); 2) a mechanism that alters gene frequencies from one generation

190 to the next (e.g., female preference for a specific call frequency); and 3) evidence that changes in

191 the light and or sound regime are causal agents driving the relationship the between heritable

192 response and the change in gene frequency in the population (e.g., a novel sound changes female

193 preference, which in turn drives changes in call structure). We briefly review additional

194 conditions for evolutionary change with respect to the four most commonly recognized forces of

195 evolution: selection, gene flow, drift, and mutation. These four mechanisms can operate

196 concurrently on the same population in environments influenced by light and noise.

\section{Sensory stimuli as drivers of selection}

198 Artificial light and noise can influence survival [28] and reproduction [32,47] of several animal

199 taxa. Numerous traits are associated with or depend upon animals' sensory systems; thus

200 evolutionary responses to these sensory stimuli will likely carry over to additional life history

201 traits. For example, both sound and light stimuli alter the configuration of communication

202 systems [15], which could influence other behavioural (e.g., agonistic interactions, mate choice, 203 vigilance, foraging efficiency), morphological (reception and production), and physiological

204 traits (e.g., stress hormone, immune function, metabolism). 
206 responses (Table 1). Two traits with moderate heritability and phenotypic change are bird song

207 and circadian rhythms. Birdsong in noisy habitats, for example, can have altered structure,

208 timing, amplitude, and frequency parameters [12]. Some components of song production are

209 heritable, such as vocal processing regions of the brain [48] and beak morphology [49].

210 Interpretation of these observations, however, are complicated by the fact that the syntax and

211 note structure of bird song is learned in most of the species studied [50], confounding field

212 estimates of heritability. Furthermore, several studies demonstrate that some vocal adjustments

213 in response to noise are likely the result of immediate behavioural flexibility and not adaptive

214 change [24]. It is possible that this behavioural flexibility could still be a leader for evolutionary

215 change (Figure $2 \mathrm{c}$ ). We posit that birdsong remains a likely trait under selection by

216 anthropogenic sensory stimuli and that the use of cross-fostering experiments in the laboratory

217 paired with field manipulations could prove a powerful approach to unveiling the strength of

218 noise as a selective agent.

219 Stronger evidence for adaptive change comes from altered light regimes. Circadian

220 rhythms are likely targets of selection because they are ubiquitous in almost all organisms and

221 synchronize to the external environment, with light as the primary zeitgeber. Although the

222 molecular basis of circadian clocks is highly conserved across taxa [16], heritable variation in

223 circadian rhythms is found within populations [51]. In the great tit (Parus major), for example,

224 circadian period length can be highly heritable $\left(\mathrm{h}^{2}=0.86\right)$ and in relatively closely related blue

225 tits (Cyanistes caeruleus), males that sing early have increased annual reproductive output by

226 increasing their extra-pair copulation success [32]. Because both tit species and several other

227 songbirds are known to begin singing earlier in the morning due to artificial light [32], artificial 
228 night lighting might select for earlier chronotypes in birds. Indeed, Dominoni et al. [52]

229 demonstrated that European blackbird (Turdus merula) urban and rural populations differ in their

230 circadian rhythms and chronotypes as would be expected from the influence of artificial light.

231 Nevertheless, even in these cases it is difficult to distinguish the sources of variation: how much

232 is due to heritable change and how much to plasticity and flexibility? Traits that are likely under

233 selective pressure from anthropogenic light and sound should be studied using pedigree and

234 animal model studies in the field to directly quantify heritable variation and infer the remaining

235 flexibility and plasticity (Box 1). Critical experimental manipulations of sound and light stimuli

236 are also needed to unambiguously identify mechanisms; stimuli that represent relevant changes

237 that populations experience from various forms of human development should be used (Box 3).

\section{Sensory stimuli as drivers of gene flow}

239 Although gene flow is often interpreted as a homogenizer of connected populations, we propose

240 that differential dispersal and migration caused by changes in anthropogenic light and noise

241 could create biased gene flow. This could result in systematic genetic differences among

242 populations along light and sound level gradients. We know that the settlement, dispersal, and

243 migration patterns of many organisms are influenced by sound [53] and light [27,34]. We are

244 not, however, aware of investigations into whether these altered patterns of movement, and any

245 subsequent gene flow, have created genetic population differentiation. Disentangling genetic

246 differentiation due to noise or light versus other human-induced environmental changes

247 represents a promising avenue for research.

248 It is also possible that anthropogenic sensory stimuli create movement barriers and

249 reduces gene flow through habitat fragmentation. For example, birds that cannot communicate

250 effectively in noisy environments might not traverse this type of matrix. Some mammals tend to 
251 avoid artificially lit environments, which would decrease connectivity [31]. A reduction in gene

252 flow could accelerate local adaptation to altered light and sound regimes but could also lead to a

253 loss of genetic variance in the long term.

\section{Sensory stimuli as drivers of genetic drift}

255 As we generally predict that increasing anthropogenic light and sound will fragment populations,

256 we expect that effective population size could be reduced in some localities, such as in many bird

257 populations in noisy areas [54]. This fragmentation could create a population bottleneck where

258 drift processes can have substantial consequences for populations, especially in terms of

259 decreased genetic variance. These ideas have yet to be explored empirically.

\section{Sensory stimuli as drivers of mutation}

261 Environmental stimuli can promote genetic mutations. Moderate and loud noise can increase

262 oxidative damage in several tissues of the body [55], which could induce mutations in the

263 germline of various taxa [56]. Increased noise could therefore directly induce germline mutations

264 and affect gene frequencies over time. Some evidence indicates that extremely loud sounds (90-

$265120 \mathrm{~dB}$ SPL) can lead to gross malformations of sperm in rats [57]. Few organisms experience

266 such extreme noise exposure levels in the wild; whether chronic exposure to less extreme noise

267 levels has similar effects represents a gap in our knowledge.

268 In parallel with the noise literature, there is laboratory evidence that light exposure,

269 especially in ultraviolet wavelengths, increases the probability of genetic mutations, including

270 within the germ lines of several taxa [58]. Thus, the mutagenic potential of anthropogenic

271 ultraviolet light, such as that produced by mercury vapor lamps, represents yet another area

272 requiring investigation. While alterations of mutation rates are likely not large enough to affect 
273 rapid evolutionary change, we would be remiss to ignore the possible effects of anthropogenic

274 sensory stimuli on direct mutation.

\section{Macroevolutionary patterns}

276 The exploration of macroevolutionary patterns evident since the onset of industrial production of

277 light and sound should provide candidate systems for comparative analysis of population-level

278 and species-level responses.

\section{Recent divergence and phylogenetic trees}

280 A surge of research has predicted biodiversity scenarios for the near future based on

281 anthropogenic change [59]. This work has primarily focused on projecting species distributions

282 in relation to climate change. A similar approach should be applied to noise and light pollution

283 now that large-scale, fine-resolution spatial data on these stimuli are now available [7,60]. One

284 approach could include the construction of maps estimating background (pre-industrialization)

285 diversification and extinction rates for individual clades known or hypothesized to be influenced

286 by noise and light. Diversity data could then be used to determine whether contemporary rates

287 for species in particular sensory environments are different from background rates [61].

288 Phylogenies are useful for examining whether selection is occurring between sister

289 species (or species groups) that exhibit different sensitivities to light or sound. Studies on

290 mammals [62] and fish [63] have shown differential selection on visual transduction network

291 (VTN) genes in species from habitats with differing amounts of light. Genes associated with

292 light can be obtained from visual gene databases, including opsins and other genes in the VTN

293 [64]. Annotated genomes permit the identification of candidate genes and allow for the

294 determination of gene function. 
296 As celestial signals like the Milky Way disappear and night is replaced by extended twilight,

297 species specialized for night-time conditions are likely to be extirpated and species flexible in

298 their behaviour with respect to light will benefit [65]. Direct mortality from night lighting can be

299 significant at the population level. For example, fatal attraction to lights has resulted in the

300 extinction of at least two populations of the endangered giant water bug Lethocerus deyrolli [66].

301 Additionally, if not offset by rescue efforts, the attraction of young seabirds to urban lights could

302 extirpate Cory's shearwater Calonectris diomedea from the Azores [67]. Well-known declines of

303 nocturnal insects, such as moths [68], have been linked to artificial night lighting, yet it is

304 unclear whether this stimuli or other human-induced environmental changes are most

305 responsible. Declines among many taxa might be due to attraction and "entrapment" at lights, but

306 for some taxa, declines could also reflect interference with sexual signals (e.g., moths [29] or

307 fireflies). Indeed, firefly species richness is lower in areas characterized by 0.2 lux and higher 308 [69].

309 Noise also has potential to drive local extirpation and possibly extinction as evidenced by

310 diversity declines and avoidance of loud areas $[13,14]$. Among birds noise sensitivity is non-

311 random; species that experience the most vocalization interference from noise and those with

312 animal-based diets are most sensitive [54]. Because range size is often negatively correlated with

313 extinction risk [70], an urgent next-step will be to identify species with small ranges that have

314 undergone extensive transformations in altered sound and light levels. Doing so should prove

315 fruitful for evaluating the roles of impaired gene flow and drift in explaining evolutionary

316 responses to these novel stimuli. 


\section{Implications for conservation and biodiversity}

319 The most immediate threat from anthropogenic noise and light is the loss of species that are

320 unable to adapt to their altered environment [11]. For example, disturbance from increased noise

321 and or light might convert some populations from sources to sinks through an inability to attract

322 mates or failed mating attempts [24], reduced physical fitness via elevated stress [71], or a

323 diminished ability to detect potential predators [11]. The loss of species might also have a

324 cascading effect on ecosystem function, such as altered rates and patterns of predation [14],

325 pollination and seed dispersal [23]. Despite mounting evidence that anthropogenic noise and

326 light negatively affects populations and communities, these stimuli are rarely considered in

327 conservation planning and restoration efforts.

328 Much less is known about how anthropogenic noise and light might influence evolution

329 and the potential implications for conservation. Behavioural responses to noise and light

330 exposure could result in the selection of maladaptive traits and the formation of evolutionary

331 traps [11]. In other cases, excessive noise and light can interfere with the acoustic and visual

332 communication used for mate selection, potentially resulting in the selection of lower quality

333 mates and reduced individual fitness [72]. It is also important to note that some species might

334 improve fitness through adaptation to louder and brighter environments, resulting in rapid

335 population increases and the emergence of a highly abundant pest species [73].

336 Evolution occurs on a timescale that is at odds with the immediacy of conservation

337 efforts. Stimuli that alter the intensity, duration, and cycles of natural sound and light

338 environments, however, have the potential to drive profound and rapid evolutionary change. As

339 anthropogenic changes to sound and light are so large relative to natural fluctuations, we propose

340 that human-induced light and sound might be particularly effective agents of selection. 
341 Understanding how noise and light might drive selection, as we propose, is a priority for a world

342 that is, unfortunately, increasingly loud and bright.

\section{Acknowledgements}

344 This manuscript was prepared as an outcome of a meeting convened at and funded by the

345 National Evolutionary Synthesis Center (National Science Foundation EF-0905606) to PIs CBC,

346 JRB, CDF. JRB and CDF were also supported by National Science Foundation Grant CNH-

3471414171.

348 


\section{Figure legends}

350

351 Figure 1. Increasing anthropogenic night lighting and sound levels represent a global

352 phenomenon that constitutes environmental changes unprecedented in the history of life on

353 Earth. (A) Europe at night. Areas colored blue are emitting an amount of light upwards that are

354 comparable to moonlight, pink areas are brighter than moonlight, and white areas are many times

355 brighter than moonlight. (B) Light is extremely heterogeneous at both landscape and local (few

356 meters) spatial scales. (C) Estimated sound levels (L50 SPL dB(A) re 20 $\mu$ Pa) created by human

357 activities that exceed background levels created by natural sources [7]. (D) Temporal

358 heterogeneity in anthropogenic sounds as a 24-hr spectrogram, which illustrates acoustic energy

359 across the frequency spectrum for 24-hrs, with each row representing 2-hrs. Lighter colors reflect

360 higher sound levels. Brighter colors prominent in the fourth row (i.e., beginning at 6am) through

361 the final row display anthropogenic sounds from road traffic and aircraft in Grand Teton

362 National Park in late September of 2013. (A) Image and Data processing by NOAA's National

363 Geophysical Data Center, (B) courtesy Freie Universität Berlin \& (C) modified from Mennitt et

364 al. [7]. Both (C) and (D) are courtesy of the U.S. National Parks Natural Sounds and Night Skies

365 Division.

366

367 Figure 2. Framework for evaluating how anthropogenic night lighting and sound can influence

368 behavioural, developmental, and evolutionary outcomes. (A) Anthropogenic light at night and

369 sound share many features relevant to animal sensory systems. Listed are only a few candidate

370 features of noise and light important to investigating the potential strength of these stimuli as

371 agents of ecological and evolutionary change, whether alone or combined given that these 
372 stimuli often co-vary in many environments. See Francis \& Barber [11] for a review of some of

373 these features. Because these stimuli can co-occur in many environments, we propose that

374 human alterations of light and sound can act synergistically on wildlife. (B) Effects of

375 anthropogenic sound and night at light are known or hypothesized to affect many levels of

376 biological organization, which could result in evolutionary change via different pathways, such

377 as selection, drift or epigenetic inheritance. Table 1 provides a more comprehensive list of

378 known and hypothesized ecological and evolutionary outcomes due to noise and light. (C)

379 Influences of anthropogenic sound and light at different levels of biological organization can

380 result in short-term behavioural flexibility, developmental plasticity, and microevolutionary

381 responses via different evolutionary forces (see Potential Microevolutionary Responses section)

382 and induce responses by individuals and populations over different spatial scales. Importantly,

383 shorter-term phenotypic responses could lead to genetic (evolutionary) change through processes

384 of genetic assimilation and accommodation, which could make evolved responses occur faster

385 or, alternatively, could weaken selection if all genotypes experience high fitness as a result of

386 sound or light-induced behavioural and developmental shifts.

387

388 Figure 3. (A) Example reaction norms of phenotypic responses to anthropogenic sound and light.

389 Each line represents the phenotype expressed by a different genotype in the population, across an

390 environmental gradient. The slope of the response represents the developmental plasticity of a

391 genotype. The error bars on each reaction norm represent behavioural flexibility as an individual

392 can alter their phenotype through behavioural mechanisms independently of developmental

393 plasticity. The distance between the lines at any given level of stimulus represents heritable

394 variation, as these are differences in phenotypic expression among the genotypes in the 
395 population. (B) Behavioural and developmental responses to anthropogenic sound and light 396 could influence patterns of divergence (modified from Lema [74]. Black line denotes mean 397 phenotypic trait value and grey lines reflect the range of trait variation under natural light and 398 sound regimes. Anthropogenic sound or light could generate rapid phenotypic divergence by 399 triggering behavioural or developmental responses well outside of the range of variation in 400 environments without these stimuli (dashed horizontal line). Rapid phenotypic change via 401 developmental or behavioural mechanisms can occur when a population colonizes an 402 environment characterized by novel light and sound regimes or if these stimuli are rapidly 403 introduced to an existing population. These novel phenotypes (blue line = mean trait value, light 404 blue $=$ range of expression) might then become canalized in the new environment (e.g., genetic 405 assimilation). 
Table 1. Numerous traits are candidates for selection by light at night and anthropogenic noise and span behaviour, morphology and physiology, some of which are directly related to phenology. The sample list below identifies candidate traits by category and selective pressure (artificial night lighting and noise) and provides evidence, if available, for observed phenotypic changes and heritability estimates for each trait.

\begin{tabular}{|c|c|c|c|c|}
\hline Trait Category & Selective Pressure & Candidate Traits & Phenotypic Change & Heritability estimates \\
\hline \multirow{8}{*}{$\begin{array}{l}\text { Communication } \\
\text { and behaviour }\end{array}$} & \multirow{8}{*}{$\begin{array}{l}\text { Acoustical environment can } \\
\text { mask or interfere with vocal } \\
\text { signals, or be timed to } \\
\text { interfere with vocal } \\
\text { signalling }\end{array}$} & $\begin{array}{l}\text { Vocal signal features } \\
\text { (frequency, timing, } \\
\text { amplitude) }\end{array}$ & $\begin{array}{l}\text { Sound level-dependent } \\
\text { frequency use, increased } \\
\text { amplitude [12] }\end{array}$ & $\begin{array}{l}\text { Song control nuclei: HVC } \\
\text { volume } h^{2}=0.38, R A \\
\left.\text { volume } h^{2}=0.72\right)[48]\end{array}$ \\
\hline & & Signal modality & $\begin{array}{l}\text { Switch to emphasize visual } \\
\text { cues in high noise [75] }\end{array}$ & Not reported \\
\hline & & Agonistic interactions & $\begin{array}{l}\text { Males respond differently to } \\
\text { urban songs [12] }\end{array}$ & $\begin{array}{l}\text { Aggression, } h^{2}=0.10(20) ; \\
\text { exploratory behaviour, } h^{2}= \\
0.54[76]\end{array}$ \\
\hline & & Mate choice & $\begin{array}{l}\text { Preference for low frequency } \\
\text { songs erodes with urban noise } \\
\text { [72]; noise decreases } \\
\text { preference for own mate [77] }\end{array}$ & Not reported \\
\hline & & Vigilance & $\begin{array}{l}\text { Increased vigilance behaviour in } \\
\text { noise [78] }\end{array}$ & Vigilance, $h^{2}=0.08[79]$ \\
\hline & & Foraging efficiency & $\begin{array}{l}\text { Successful foraging bouts } \\
\text { decreased and foraging time } \\
\text { increased near noisy roads [80] }\end{array}$ & $\begin{array}{l}\text { Proportion of prey } \\
\text { captured in neonates, } h^{2}= \\
0.32-0.54[81]\end{array}$ \\
\hline & & Learning and cognition & $\begin{array}{l}\text { Reduced learning after noise } \\
\text { exposure [55] }\end{array}$ & $\begin{array}{l}\text { Learning in bees, } \mathrm{h}^{2}= \\
0.39-0.54[82]\end{array}$ \\
\hline & & Sound production & $\begin{array}{l}\text { Coupling of amplitude and } \\
\text { frequency such that both } \\
\text { increase in urban noise [83] }\end{array}$ & $\begin{array}{l}\text { Beak length, depth, and } \\
\text { width, } h^{2}=0.65-0.90[49]\end{array}$ \\
\hline
\end{tabular}


Rates and timing of signalling

Timing of dawn song

Timing of reproduction

Feeding behaviour

Exposure to light at night around dawn and dusk, and to low light levels at night

Nest site choice

Reproduction

Calling and movement behaviour

Emergence time

Daily timing of feeding behaviour

Acoustical environment can Sound reception

mask or interfere with vocal

signals

Morphology

Exposure to light at night

Eye size

Body mass

Stress hormones

Physiology
Exposure to increased acoustical noise ncreased signalling at times without high noise [84]

Endogenous circadian period length, $h^{2}=0.86$ [51]

Advance of dawn song, altered attractiveness male birds [32]

Advancement of reproductive physiology of blackbirds [18]

Increase of chick feeding

behaviour in great tits [85]

Avoidance of light at nest sites

by godwits [86]

Alteration of mating behaviour in moths [29]

Reduced advertisement call activity, less movement activity

[87]

Delayed emergence time [88] Not reported

Switch to nocturnal feeding [30] Not reported

Individuals respond differently

to attenuated versions of vocal

Hearing loss, $\mathrm{h}^{2}=0.36$

signals [89]

Reduced eye size

Eye size, $\mathrm{h}^{2} \leq 0.5[91]$

Reduced mass of juveniles [88] Not reported

Elevated corticosterone levels

Corticosterone levels, $\mathrm{h}^{2} \leq$

[92]

Metabolism

Increased oxidative damage in Not reported noise [55] 
Cardiovascular health

Stress hor
melatonin

Timing of reproduction moult

Exposure to low light levels

at night

Immune system
Increased occurrence of

hypertension and

cardiovascular disease in

\section{humans [94]}

Reduced expression of

melatonin, change of pattern of

hormone expression [95]

Early onset of gonadal growth, temporal organization of moult

[18] challenges: delayed-type

hypersensitivity, induced fever, bactericide activity blood [17]

Pheromone release
Suppression of pheromone release
Not reported

\section{As above}

\section{Not reported}

Not reported

Not reported 


\section{Text Boxes}

2

\section{Box 1. How to measure heritability in the field}

4 To estimate heritability in wild populations we need to disentangle the observed variation in a

5 trait between genetic and environmental components. Also, within the genetic variance it is often

6 useful to directly estimate the narrow-sense heritability, which tells us how much of variance is

7 due to additive genetic effects (of multiple loci influencing a complex quantitative trait), and is

8 estimated by comparing relatives with each other. In particular, we advocate for animal model

9 approaches to estimating heritability [96]. In such a technique, information about genetic

10 relatedness of individuals in populations is collected to construct pedigrees that are then analysed

11 using generalized linear model approaches that partition phenotypic variance among possible

12 genetic explanations. One of the advantages of this approach over others is that some statistical

13 models can use incomplete pedigrees that include quite distant relationships, making the methods

14 fairly amenable to estimating heritability from field population datasets [96]. Many of the traits

15 we propose could evolve in relation to altered anthropogenic light and sound are close to

16 Gaussian-distributed (Table 1), therefore it appears that maximum likelihood approaches to

17 estimating heritability through animal models could be most appropriate in many cases [97]. 


\section{Box 2. Measurement of light and sound: challenges and recommendations}

20 In contrast to scalar variables like temperature or concentration of a chemical substance, the

21 spectral and vector nature of both light and sound make measurement more challenging,

22 particularly in field settings. There are also many different units of measurement, which are

23 likely not familiar to many ecologists and evolutionary biologists (e.g. illuminance vs. spectral

24 radiance). Past studies have often opted to use a simple, inexpensive metric, but in many cases

25 wrong instrument choice can lead to incorrect conclusions. As an example, in many cases it

26 might not be the overall light or sound level that is important, but rather a signal-to-noise ratio.

27 In vision, for example, scenes with identical irradiance can have vastly different levels of

28 contrast and glare.

\section{Challenges}

30 - Range: Both light and sound vary over many orders of magnitude, changing on a

31 timescale of seconds to minutes. Sound is measured on a logarithmic scale, as is light in

32 astronomy.

33 - Direction of wave propagation: Animal responses usually depend not only on integrated

34 fluxes, but also directional information. Glare and contrast can be critical in artificially lit

35 scenes.

36 - Spectral weighting: human perception does not necessarily match animal perception, but

37 full spectral measurement is expensive and difficult.

38 - Short duration variations: Amplitude and frequency modulation might need to be

39 measured for sound, flicker could be important for artificial light. 
40 - Location of measurement: Ideally, both noise and light exposure should be measured

41 directly on the target animal, although this can be expensive and time-consuming. If not

42 possible, then the measurement should be done as close as possible to the animal's core

$43 \quad$ area.

\section{Recommendations:}

45 - Tradeoffs must be assessed in the planning stage to find a measurement technique that is

46 appropriate to answer the question under investigation. Recording spectral information is

47 highly recommended. Tradeoffs are more acceptable in field experiments, where

48 conditions can be highly variable. Full spectral characterization should be standard in

49 laboratory studies [98].

50 - Instruments must have sufficient range and precision. Measurements at the edge of an

51 instrument's range provide insufficient information.

52 - It is likely unnecessary and unproductive to develop mastery in an outside discipline.

53 Find collaborators from outside of your field to provide advice and assistance in

54 measurement. Similar to consulting a statistician, experimental setup should be discussed

55 with a professional (e.g., a lighting or acoustical engineer). 


\section{Box 3. Suitable study systems or potential traits under selection}

59 Numerous traits are potentially under selective pressure by anthropogenic light and sound (Table

60 1). The challenge is to actually show selection and microevolutionary responses. The relation

61 between traits and reproductive fitness is ideally studied experimentally via controlled treatments

62 to light and sound stimuli alone and combined in an otherwise unchanged environment. A good

63 approach is the assessment of genetic and phenotypic diversity in a species with discrete

64 populations in urban and natural areas. This can be studied directly in an integrated manner by

65 looking at morphology, behaviour, physiology and (single nucleotide) polymorphisms, and

66 connected selective sweeps. Yet areas exposed to novel noise and light regimes, such as urban

67 areas, are often influenced by many other environmental factors. A more powerful design is to

68 experimentally test individuals from populations in both environments in a new, controlled setup

69 for differences in responses to urban stimuli such as light and sound and focusing on candidate

70 genes linked to traits hypothesized to be under selection or by using genome scanning

71 approaches. Indeed, such "common garden" experiments have revealed important information on

72 differences between urban and wildland populations [99]. It is critical, however, to test whether

73 these differences persist in successive generations. Conducting such studies in the field or

74 laboratory will be challenging, especially for organisms that have low fecundity and are long-

75 lived. For these organisms, selection might only occur after considerable time or not at all given

76 that slower life histories could have lower evolutionary potential in the face of rapid

77 environmental change [100]. Nevertheless, numerous taxa with traits likely under selection by

78 anthropogenic sound and light and with higher evolutionary potential could be studied over

79 shorter timeframes (Table 1).

80

81 


\section{Glossary}

83 Background extinction rates: pre-human rates of extinction outside of recognized mass extinction

84 events.

85 Background speciation rates: pre-human rates of speciation outside of the recovery period

86 following mass extinction events.

87 Behavioural Flexibility: Immediate adjustments of behaviour and physiology in response to

88 environmental conditions.

89 Developmental Plasticity: A single genotype's change in developmental trajectory and

90 phenotypic outcome in response to a different environmental condition.

91 Heritability: The proportion of phenotypic variance attributable to genetic variance.

92 Macroevolution: The study of patterns and processes of evolution that occur at or above the level

93 of species.

94 Microevolution: Change in allele frequencies in a population over time.

95 Reaction Norm: Depiction of the range of phenotypes expressed by a single genotype across

96 different environments.

97 Zeitgeber: Any external cue that entrains an organisms' biological rhythms to environmental

98 cycles.

99

100 


\section{Literature Cited}

102

103 1. Sih, A., et al. (2011) Evolution and behavioural responses to human-induced rapid

104 environmental change. Evol. Appl. 4, 367-387.

105 2. Barber, J.R., et al. (2010) The costs of chronic noise exposure for terrestrial organisms.

106 Trends Ecol. Evol. 25, 180-189.

107 3. Davies, T.W., et al. (2014) The nature, extent, and ecological implications of marine light 108 pollution. Front. Ecol. Environ. 12, 347-355.

109 4. Cinzano, P., et al. (2001) The first world atlas of the artificial night sky brightness. Mon.

$110 \quad$ Non. R. Astron. Soc. 328, 689-707.

111 5. Kyba, C.C.M., et al. (2015) Worldwide variations in artificial skyglow. Sci. Rep. 5, 8409.

112 6. Chepesiuk, R. (2005) Decibel hell: the effects of living in a noisy world. Environ. Health 113 Perspect. 113, A34-A41.

$1147 . \quad$ Mennitt, D.J., et al. (2013) Mapping sound pressure levels on continental scales using a 115 geospatial sound model. In Proceedings of Inter-Noise, pp. 1-11.

116 8. Hildebrand, J.A. (2009) Anthropogenic and natural sources of ambient noise in the ocean. 117 Mar. Ecol. Prog. Ser. 395, 5-20.

$1189 . \quad$ Aubrecht, C., et al. (2008) A global inventory of coral reef stressors based on satellite 119 observed nighttime lights. Geocarto Int. 23, 467-479.

120 10. Dawson, T.P., et al. (2011) Beyond predictions: biodiversity conservation in a changing $121 \quad$ climate. Science 332, 53-58.

122 11. Francis, C.D. and Barber, J.R. (2013) A framework for understanding noise impacts on 123 wildlife: an urgent conservation priority. Front. Ecol. Environ. 11, 305-313. 
124 12. Slabbekoorn, H. (2013) Songs of the city: noise-dependent spectral plasticity in the 125 acoustic phenotype of urban birds. Anim. Behav. 85, 1089-1099.

126 13. McClure, C.J., et al. (2013) An experimental investigation into the effects of traffic noise 127 on distributions of birds: avoiding the phantom road. Proc. Roy. Soc. B: Biol. Sci. 280, $128 \quad 20132290$.

129 14. Francis, C.D., et al. (2009) Noise pollution changes avian communities and species $130 \quad$ interactions. Curr. Biol. 19, 1415-1419.

131 15. Bradbury, J.W. and Vehrencamp, S.L. (2011) Principles of Animal Communication.

132 Sinauer.

133 16. Dunlap, J.C., et al. (2004) Chronobiology: Biological Timekeeping. Sinauer Associates.

134 17. Bedrosian, T.A., et al. (2011) Chronic exposure to dim light at night suppresses immune 135 response in Siberian hamsters. Biol. Lett. 7, 468-471.

136 18. Dominoni, D., et al. (2013) Artificial light at night advances avian reproductive 137 physiology. Proc. Roy. Soc. B: Biol. Sci. 280, 20123017.

138 19. Shannon, G., et al. (2014) Road traffic noise modifies behaviour of a keystone species. 139 Anim. Behav. 94, 135-141.

140 20. Kyba, C.C.M. and Hölker, F. (2013) Do artificially illuminated skies affect biodiversity 141 in nocturnal landscapes? Landscape Ecol. 28, 1637-1640.

142 21. Halfwerk, W. and Slabbekoorn, H. (2015) Pollution going multimodal: the complex 143 impact of the human-altered sensory environment on animal perception and performance. $144 \quad$ Biol. Lett. 11, 20141051.

145 22. Chan, A.A.Y.-H., et al. (2010) Anthropogenic noise affects risk assessment and attention: 146 the distracted prey hypothesis. Biol. Lett. 6, 458-461. 
147 23. Francis, C.D., et al. (2012) Noise pollution alters ecological services: enhanced

148 pollination and disrupted seed dispersal. Proc. Roy. Soc. B: Biol.Sci. 279, 2727-2735.

149 24. Gross, K., et al. (2010) Behavioral plasticity allows short-term adjustment to a novel

150 environment. Am. Nat. 176, 456-464.

151 25. Navara, K.J. and Nelson, R.J. (2007) The dark side of light at night: physiological,

152 epidemiological, and ecological consequences. J. Pineal Res. 43, 215-224.

153 26. Warrant, E.J. (2007) Visual ecology: hiding in the dark. Curr. Biol. 17, R209-R211.

154 27. Longcore, T. and Rich, C. (2004) Ecological light pollution. Front. Ecol. Environ. 2, $155 \quad 191-198$.

156 28. Rich, C. and Longcore, T., eds (2006) Ecological Consequences of Artificial Night 157 Lighting. Island Press.

158 29. van Geffen, K.G., et al. (2015) Artificial light at night inhibits mating in a Geometrid 159 moth. Insect Conserv. Diver. 8, 282-287.

160 30. Dwyer, R.G., et al. (2013) Shedding light on light: benefits of anthropogenic illumination 161 to a nocturnally foraging shorebird. J. Anim. Ecol. 82, 478-485.

162 31. Stone, E.L., et al. (2009) Street lighting disturbs commuting bats. Curr. Biol. 19, 1123$163 \quad 1127$.

164 32. Kempenaers, B., et al. (2010) Artificial night lighting affects dawn song, extra-pair siring 165 success and lay date in songbirds. Curr. Biol. 20, 1735-1739.

166 33. Davies, T.W., et al. (2012) Street lighting changes the composition of invertebrate 167 communities. Biol. Lett. 8, 764-767. 
16834 . Longcore, T., et al. (2015) Tuning the white light spectrum of light emitting diode lamps 169 to reduce attraction of nocturnal arthropods. Philos. Trans. R. Soc. Lond. B: Biol. Sci., 20140125.

$17135 . \quad H e i l i n g$, A.M. (1999) Why do nocturnal orb-web spiders (Araneidae) search for light? 172 Behav. Ecol. Sociobiol. 46, 43-49.

173 36. Lampe, U., et al. (2014) How grasshoppers respond to road noise: developmental 174 plasticity and population differentiation in acoustic signalling. Funct. Ecol. 28, 660-668.

175 37. Badyaev, A.V. (2009) Evolutionary significance of phenotypic accommodation in novel 176 environments: an empirical test of the Baldwin effect. Philos. Trans. R. Soc. Lond. B:

177 Biol. Sci. 364, 1125-1141.

178 38. Baythavong, B.S. (2011) Linking the Spatial Scale of Environmental Variation and the 179 Evolution of Phenotypic Plasticity: Selection Favors Adaptive Plasticity in Fine-Grained $180 \quad$ Environments. Am. Nat. 178, 75-87.

181 39. Uller, T. and Helantera, H. (2011) When are genes 'leaders' or 'followers' in evolution? 182 Trends Ecol.Evol. 26, 435-436.

183 40. Borniger, J.C., et al. (2014) Exposure to dim light at night during early development 184 increases adult anxiety-like responses. Physiol. Behav. 133, 99-106.

185 41. Ciarleglio, C.M., et al. (2011) Perinatal photoperiod imprints the circadian clock. Nat. $186 \quad$ Neurosci. 14, 25-27.

187 42. Brooks, E. and Canal, M.M. (2013) Development of circadian rhythms: pole of postnatal 188 light environment. Neurosci. Biobehav. Rev. 37, 551-560. 
189 43. Clark, M.E. and Reed, W.L. (2012) Seasonal interactions between photoperiod and 190 maternal effects determine offspring phenotype in Franklin's gull. Funct. Ecol. 26, 948191958.

192 44. de Soto, N.A., et al. (2013) Anthropogenic noise causes body malformations and delays 193 development in marine larvae. Sci.Rep. 3, 2831.

194 45. Mooney, M.P., et al. (1985) Prenatal stress and increased fluctuating asymmetry in the 195 parietal bones of neonatal rats. Am. J. Phys. Anthropol. 68, 131-134.

196 46. Azzi, A., et al. (2014) Circadian behavior is light-reprogrammed by plastic DNA 197 methylation. Nat. Neurosci. 17, 377-382.

198 47. Halfwerk, W., et al. (2011) Negative impact of traffic noise on avian reproductive 199 success. J. Appl. Ecol. 48, 210-219.

200 48. Airey, D.C., et al. (2000) Variation in the volume of zebra finch song control nuclei is 201 heritable: developmental and evolutionary implications. Proc. Roy. Soc. B: Biol. Sci. 267, $202 \quad 2099-2104$.

203 49. Boag, P.T. (1983) The heritability of external morphology in Darwin's ground finches 204 (Geospiza) on Isla Daphne Major, Galapagos. Evolution 37, 877-894.

205 50. Marler, P. (1990) Song learning: the interface between behaviour and neuroethology.

206 Philos. Trans. R. Soc. Lond. B: Biol. Sci. 329, 109-114.

207 51. Helm, B. and Visser, M.E. (2010) Heritable circadian period length in a wild bird 208 population. Proc. Roy. Soc. B: Biol. Sci. 277, 3335-3342.

209 52. Dominoni, D.M., et al. (2013) Clocks for the city: circadian differences between forest $210 \quad$ and city songbirds. P. Roy. Soc. B: Biol. Sci. 280, 20130593. 
211 53. Tennessen, J.B., et al. (2014) Traffic noise causes physiological stress and impairs

212 breeding migration behaviour in frogs. Conservation Physiology 2, cou032.

213 54. Francis, C.D. (2015) Vocal traits and diet explain avian sensitivities to anthropogenic 214 noise. Global Change Biol. 21, 1809-1820.

215 55. Cheng, L., et al. (2011) Moderate noise induced cognition impairment of mice and its 216 underlying mechanisms. Physiol. Behav. 104, 981-988.

217 56. Aitken, R.J. and Curry, B.J. (2011) Redox regulation of human sperm function: from the 218 physiological control of sperm capacitation to the etiology of infertility and DNA damage 219 in the germ line. Antioxid. Redox Sign. 14, 367-381.

220 57. Jalali, M., et al. (2012) Effect of noise stress on count, progressive and non-progressive 221 sperm motility, body and genital organ weights of adult male rats. J. Hum. Reprod. Sci. 5, $222 \quad 48-51$.

223 58. Grunwald, D.J. and Streisinger, G. (1992) Induction of mutations in the zebrafish with 224 ultraviolet light. Genet. Res. 59, 93-101.

225 59. Thuiller, W., et al. (2011) Consequences of climate change on the tree of life in Europe. $226 \quad$ Nature $470,531-534$.

227 60. Kyba, C.C.M., et al. (2014) High-resolution imagery of Earth at night: new sources, 228 opportunities and challenges. Remote Sens. 7, 1-23.

229 61. Condamine, F.L., et al. (2013) Macroevolutionary perspectives to environmental change. $230 \quad$ Ecol. Lett. 16, 72-85.

231 62. Veilleux, C.C., et al. (2013) Nocturnal light environments influence color vision and 232 signatures of selection on the OPN1SW opsin gene in nocturnal lemurs. Mol. Biol. Evol. $233 \quad 30,1420-1437$. 
234 63. Terai, Y., et al. (2006) Divergent selection on opsins drives incipient speciation in Lake 235 Victoria cichlids. PLoS Biol.4, e433.

236 64. Colley, N.J. and Dowling, J.E. (2013) Spotlight on the evolution of vision. Visual $237 \quad$ Neurosci. 30, 1-3.

238 65. Nightingale, B., et al. (2006) Artificial night lighting and fishes. In Ecological 239 Consequences of Artificial Night Lighting (Rich, C. and Longcore, T., eds), pp. 257-276, $240 \quad$ Island Press.

241 66. Yoon, T.J., et al. (2010) Light-attraction flight of the giant water bug, Lethocerus deyrolli 242 (Hemiptera: Belostomatidae), and endangered wetland insect in East Asia. Aquat. Insects $243 \quad 32,195-203$.

244 67. Fontaine, R., et al. (2011) The impact of introduced predators, light-induced mortality of 245 fledglings and poaching on the dynamics of the Cory's shearwater (Calonectris 246 diomedea) population from the Azores, northeastern subtropical Atlantic. Biol. Conserv. $247 \quad 144,1998-2011$.

248 68. Conrad, K.F., et al. (2006) Rapid declines of common, widespread British moths provide 249 evidence of an insect biodiversity crisis. Biol. Conserv. 132, 279-291.

250 69. Viviani, V.R., et al. (2010) Fauna de besouros bioluminescentes (Coleoptera:

251 Elateroidea: Lampyridae; Phengodidae, Elateridae) nos municípios de Campinas, 252 Sorocaba-Votorantim e Rio Claro-Limeira (SP, Brasil): biodiversidade e influência da 253 urbanização. Biota Neotropica 10, 103-116.

254 70. Harris, G. and Pimm, S.L. (2008) Range size and extinction risk in forest birds. Conserv. $255 \quad$ Biol. 22, 163-171. 
256 71. Blickley, J.L., et al. (2012) Experimental evidence for the effects of chronic

257 anthropogenic noise on abundance of Greater Sage-Grouse at leks. Conserv. Biol. 26,

$258 \quad 461-471$.

259 72. Huet des Aunay, G., et al. (2014) Urban noise undermines female sexual preferences for 260 low-frequency songs in domestic canaries. Anim. Behav. 87, 67-75.

261 73. Palumbi, S.R. (2001) Humans as the world's greatest evolutionary force. Science 293, $262 \quad 1786-1790$.

263 74. Lema, S.C. (2014) Hormones and Phenotypic Plasticity in an Ecological Context:

264 Linking Physiological Mechanisms to Evolutionary Processes. Integr. Comp. Biol. 54, $265 \quad 850-863$.

266 75. Partan, S.R., et al. (2010) Multimodal alarm behavior in urban and rural gray squirrels 267 studied by means of observation and a mechanical robot. Current Zoology 56, 313-326.

268 76. Drent, P.J., et al. (2003) Realized heritability of personalities in the great tit (Parus 269 major). Proc. Roy. Soc. B: Biol. Sci. 270, 45-51.

$27077 . \quad$ Swaddle, J.P. and Page, L.C. (2007) High levels of environmental noise erode pair 271 preferences in zebra finches: implications for noise pollution. Anim. Behav. 74, 363-368.

272 78. Mahjoub, G., et al. (2015) Using a "sonic net" to deter pest bird species: excluding

273 European starlings from food sources by disrupting their acoustic communication. Wildl. 274 Soc. Bull.

275 79. Blumstein, D., et al. (2010) Heritability of anti-predatory traits: vigilance and locomotor 276 performance in marmots. J. Evol. Biol. 23, 879-887. 
277 80. Siemers, B.M. and Schaub, A. (2010) Hunting at the highway: traffic noise reduces 278 foraging efficiency in acoustic predators. Proc. Roy. Soc. B: Biol. Sci. 278, 1646-1652.

279 81. Gibbons, M.E., et al. (2005) Both learning and heritability affect foraging behaviour of 280 red-backed salamanders, Plethodon cinereus. Anim. Behav. 69, 721-732.

281 82. Brandes, C. (1988) Estimation of heritability of learning behavior in honeybees (Apis 282 mellifera capensis). Behav. Genet. 18, 119-132.

283 83. Nemeth, E., et al. (2013) Bird song and anthropogenic noise: vocal constraints may 284 explain why birds sing higher-frequency songs in cities. Proc. Roy. Soc. B: Biol. Sci. 280, 28520122798.

286 84. Fuller, R.A., et al. (2007) Daytime noise predicts nocturnal singing in urban robins. Biol. $287 \quad$ Lett. 3, 368-370.

288 85. Titulaer, M., et al. (2012) Activity patterns during food provisioning are affected by 289 artificial light in free living great tits (Parus major). PLoS ONE 7, e37377.

290 86. De Molenaar, J.G., et al. (2006) Road lighting and grassland birds: local influence of 291 road lighting on a black-tailed godwit population. In Ecological Consequences of 292 Artificial Night Lighting (Rich, C. and Longcore, T., eds), pp. 114-136, Island Press.

293 87. Baker, B.J. and Richardson, J.M.L. (2006) The effect of artificial light on male breeding294 season behaviour in green frogs, Rana clamitans melanota. Can. J. Zool. 84, 1528-1532.

295 88. Boldogh, S., et al. (2007) The effects of the illumination of buildings on house-dwelling 296 bats and its conservation consequences. Acta Chiropterol. 9, 527-534.

297 89. Leader, N., et al. (2005) Acoustic properties of two urban song dialects in the orange298 tufted sunbird (Nectarinia osea). Auk 122, 231-245.

299 90. Kvestad, E., et al. (2012) Heritability of hearing loss. Epidemiology 23, 328-331. 
300 91. Zhou, G. and Williams, R.W. (1999) Mouse models for the analysis of myopia: an 301 analysis of variation in eye size of adult mice. Optometry Vision Sci. 76, 408-418.

302 92. Blickley, J.L., et al. (2012) Experimental chronic noise is related to elevated fecal

303 corticosteroid metabolites in lekking male greater sage-grouse (Centrocercus $304 \quad$ urophasianus). PLoS ONE 7, e50462.

305 93. Evans, M.R., et al. (2006) Heritability of corticosterone response and changes in life 306 history traits during selection in the zebra finch. J. Evol. Biol. 19, 343-352.

307 94. Basner, M., et al. (2014) Auditory and non-auditory effects of noise on health. Lancet $308 \quad 383,1325-1332$.

309 95. Nozaki, M., et al. (1990) Diurnal changes in serum melatonin concentrations under 310 indoor and outdoor environments and light suppression of nighttime melatonin secretion 311 in the female Japanese monkey. J. Pineal Res. 9, 221-230.

312 96. Wilson, A.J., et al. (2010) An ecologist's guide to the animal model. J. Anim. Ecol. 79, $313 \quad 13-26$.

314 97. de Villemereuil, P., et al. (2013) Comparing parent-offspring regression with frequentist 315 and Bayesian animal models to estimate heritability in wild populations: a simulation 316 study for Gaussian and binary traits. Methods Ecol. Evol. 4, 260-275.

317 98. Lucas, R.J., et al. (2014) Measuring and using light in the melanopsin age. Trends $318 \quad$ Neurosci. 37, 1-9.

319 99. Atwell, J.W., et al. (2012) Boldness behavior and stress physiology in a novel urban 320 environment suggest rapid correlated evolutionary adaptation. Behav. Ecol. 23, 960-969. 
321 100. Vedder, O., et al. (2013) Quantitative assessment of the importance of phenotypic 322 plasticity in adaptation to climate change in wild bird populations. PLoS Biol.11, 323 e1001605.

324

325 


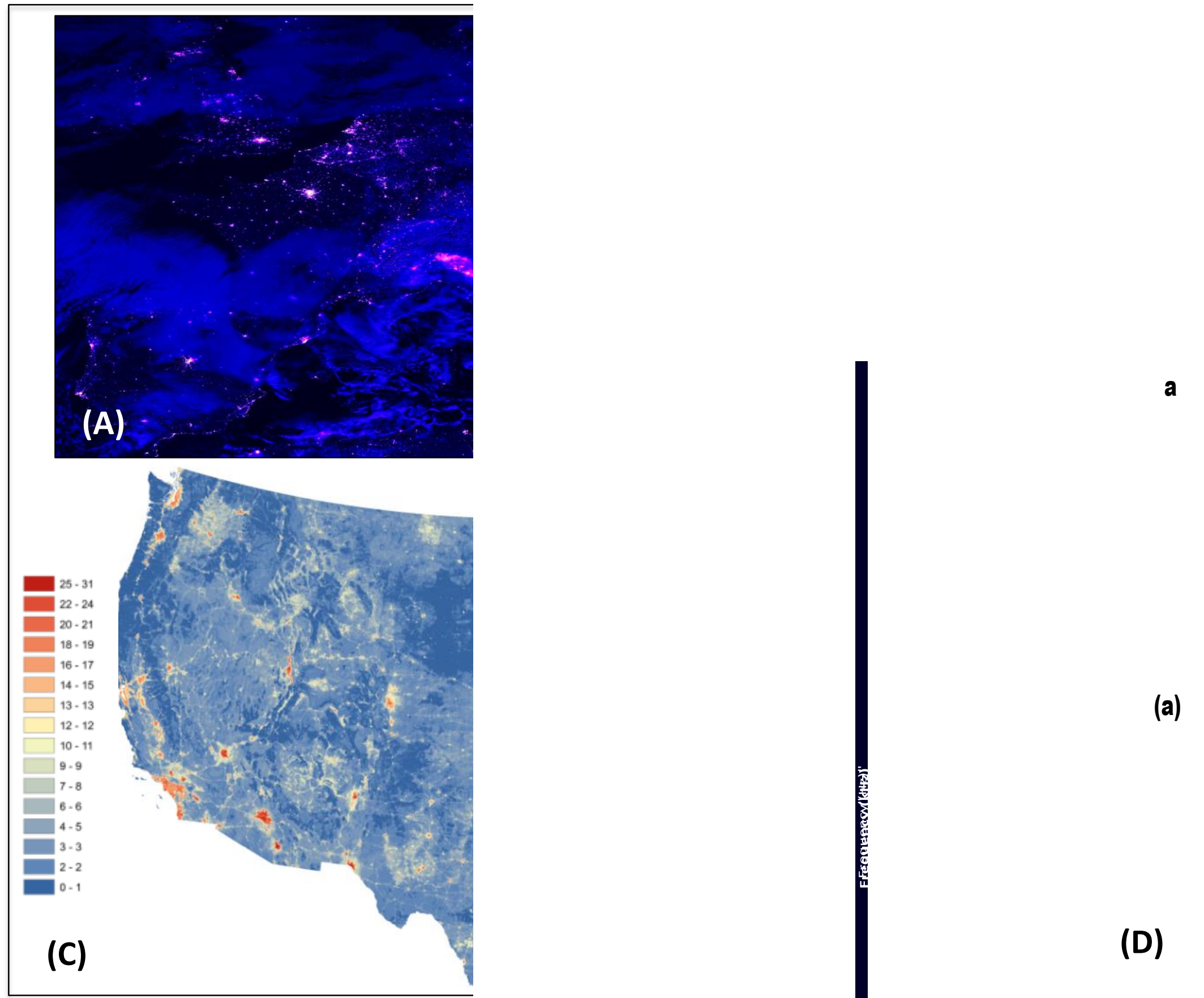




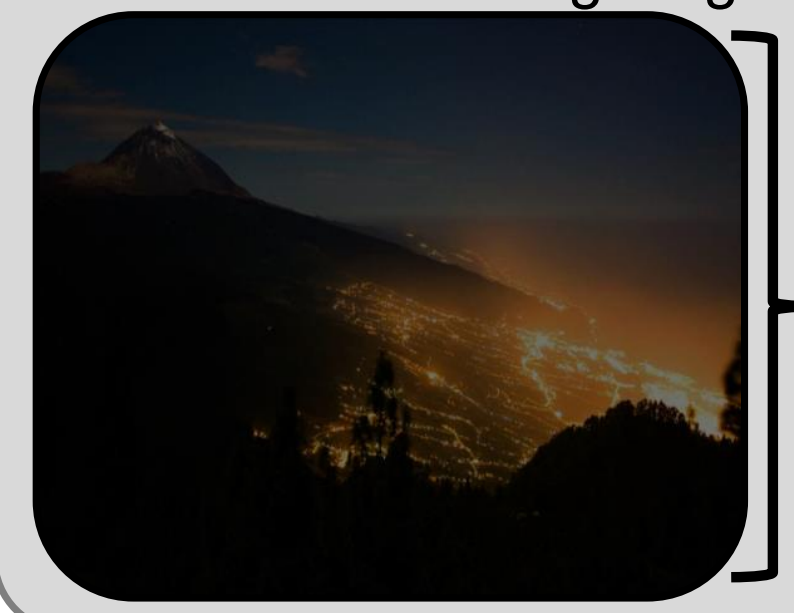

Combined effects among:

- Sensory system relevance

- Temporal overlap with key physiological and behavioral functions

- Duration, predictability, and intensity

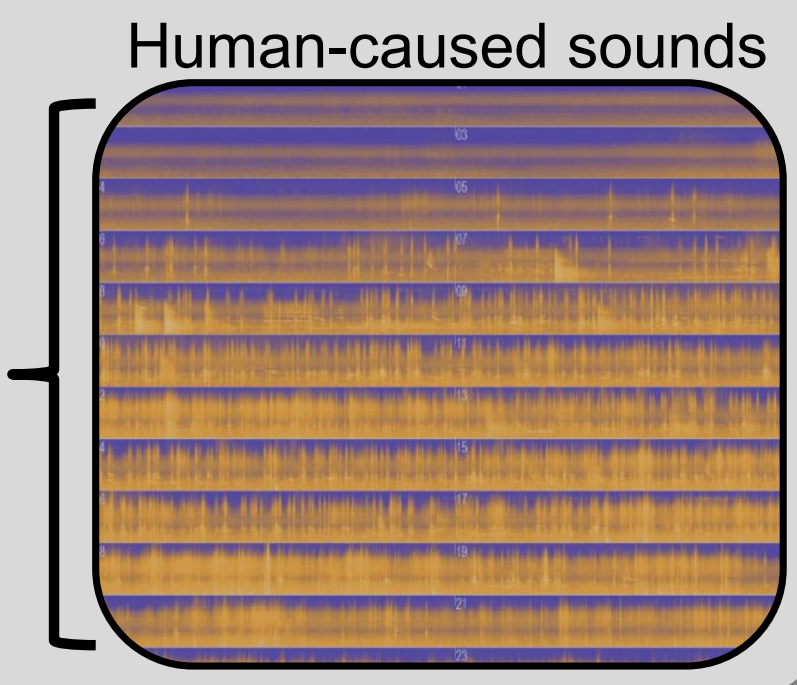

(B)

(C) Selection Epigenetic inheritance

Ontogeny

Gene expression

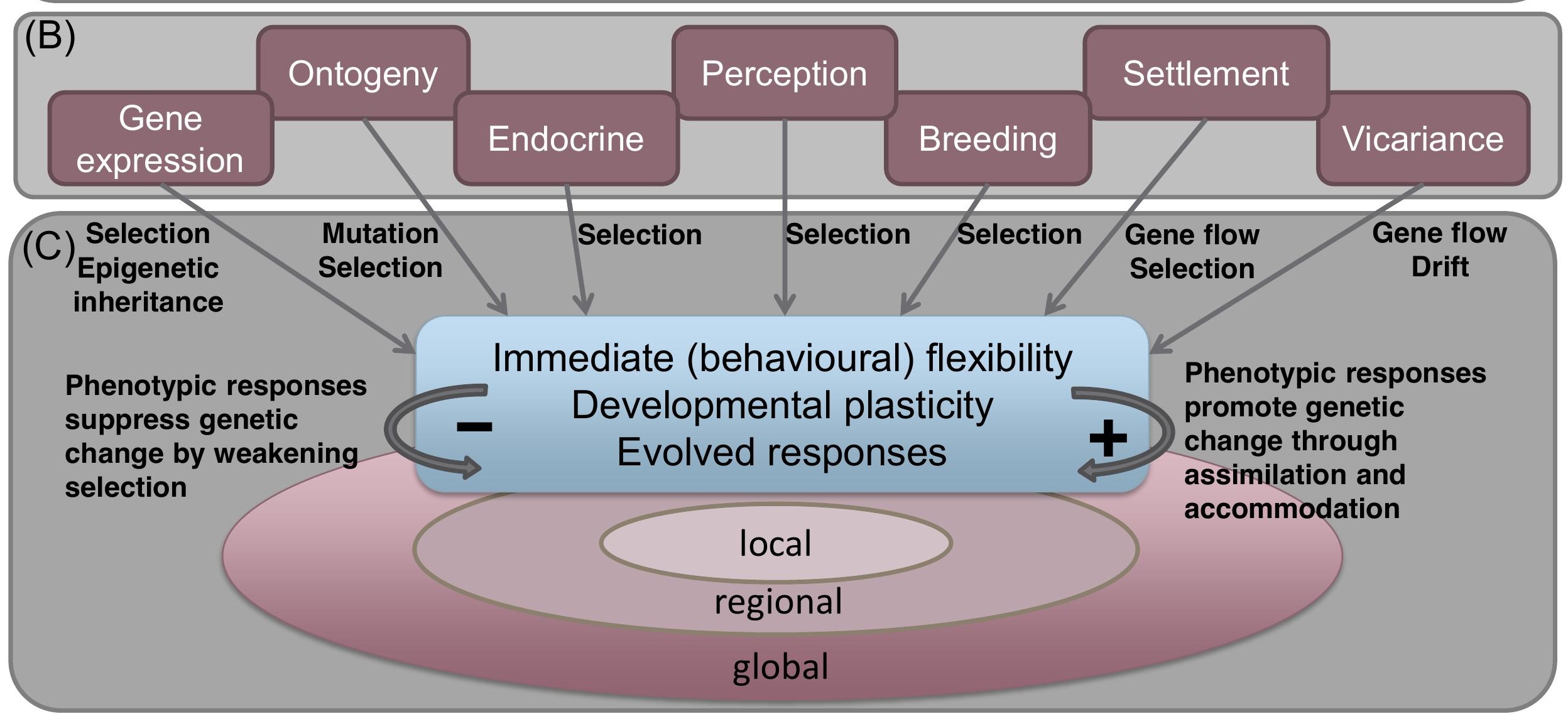

Phenotypic responses suppress genetic change by weakening selection

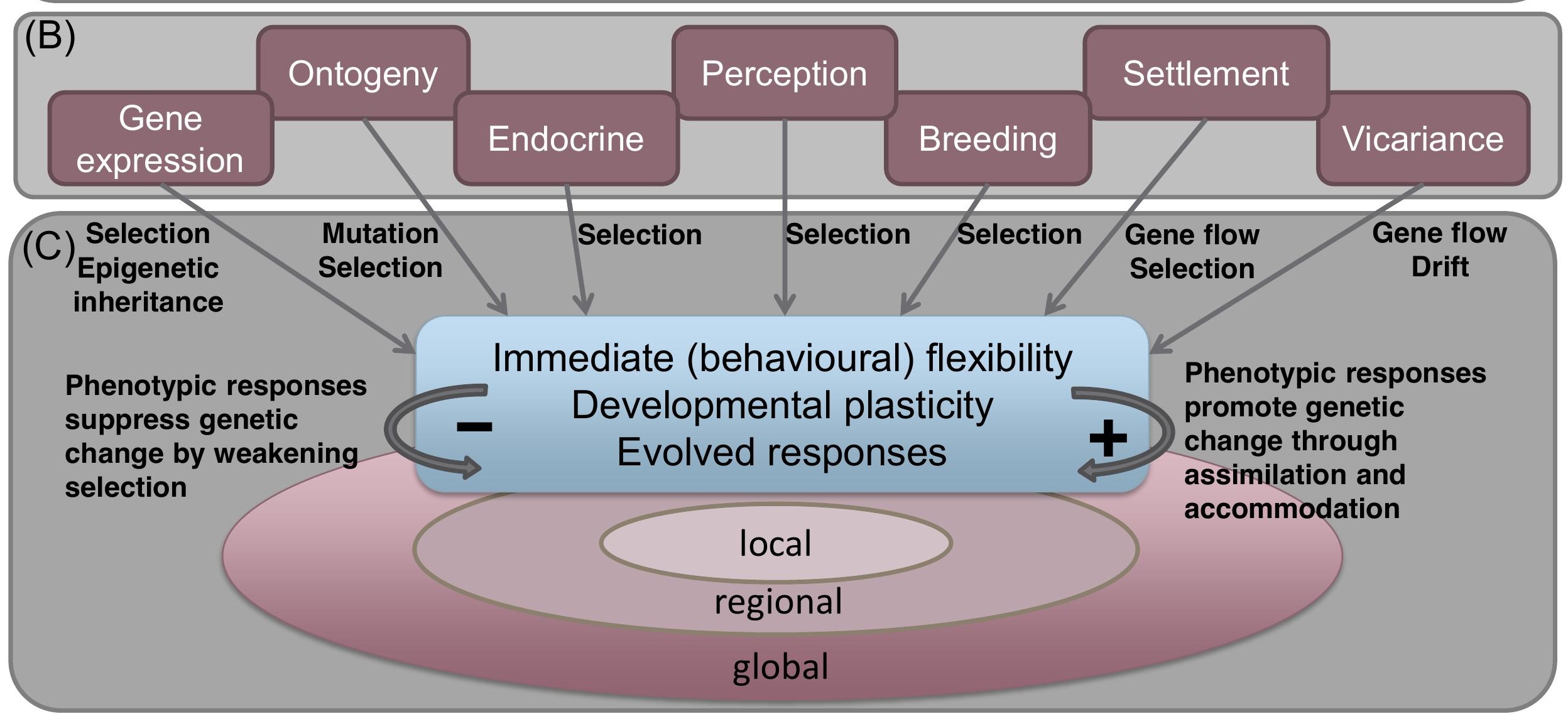

\section{Mutation} Selection Imr Immediate (behavioural) flexibility Developmental plasticity Evolved responses

global
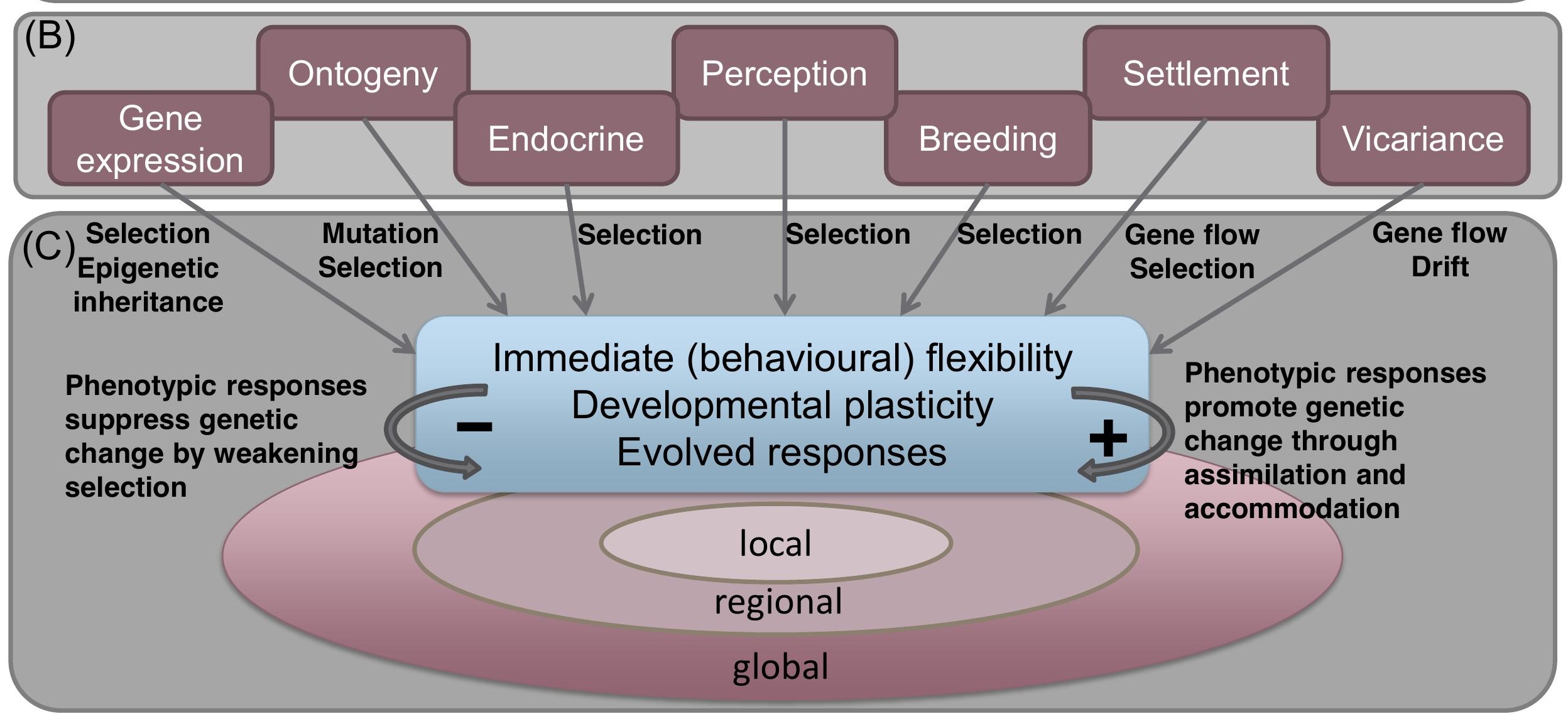

Phenotypic responses promote genetic change through assimilation and accommodation ene flow Drift
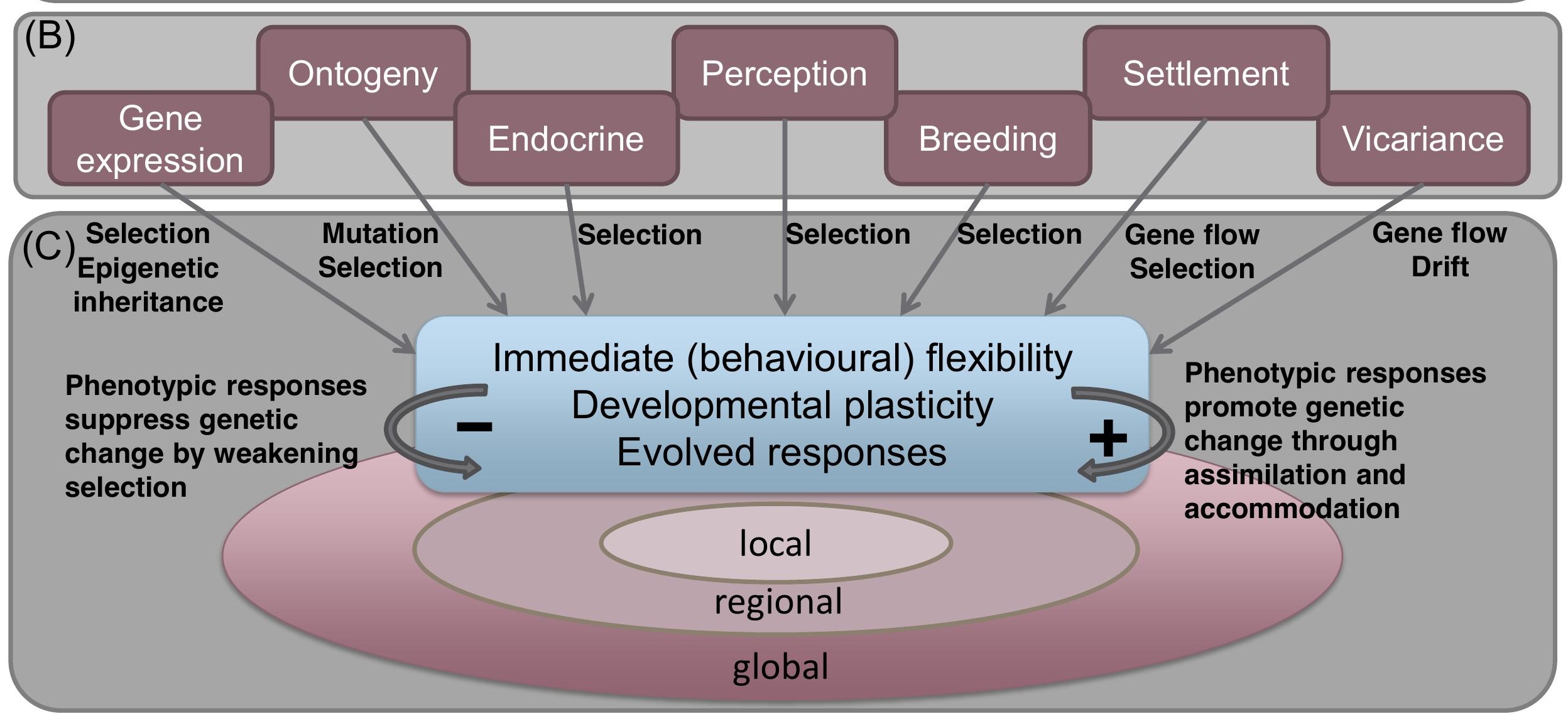

\section{Settlement}

Vicariance

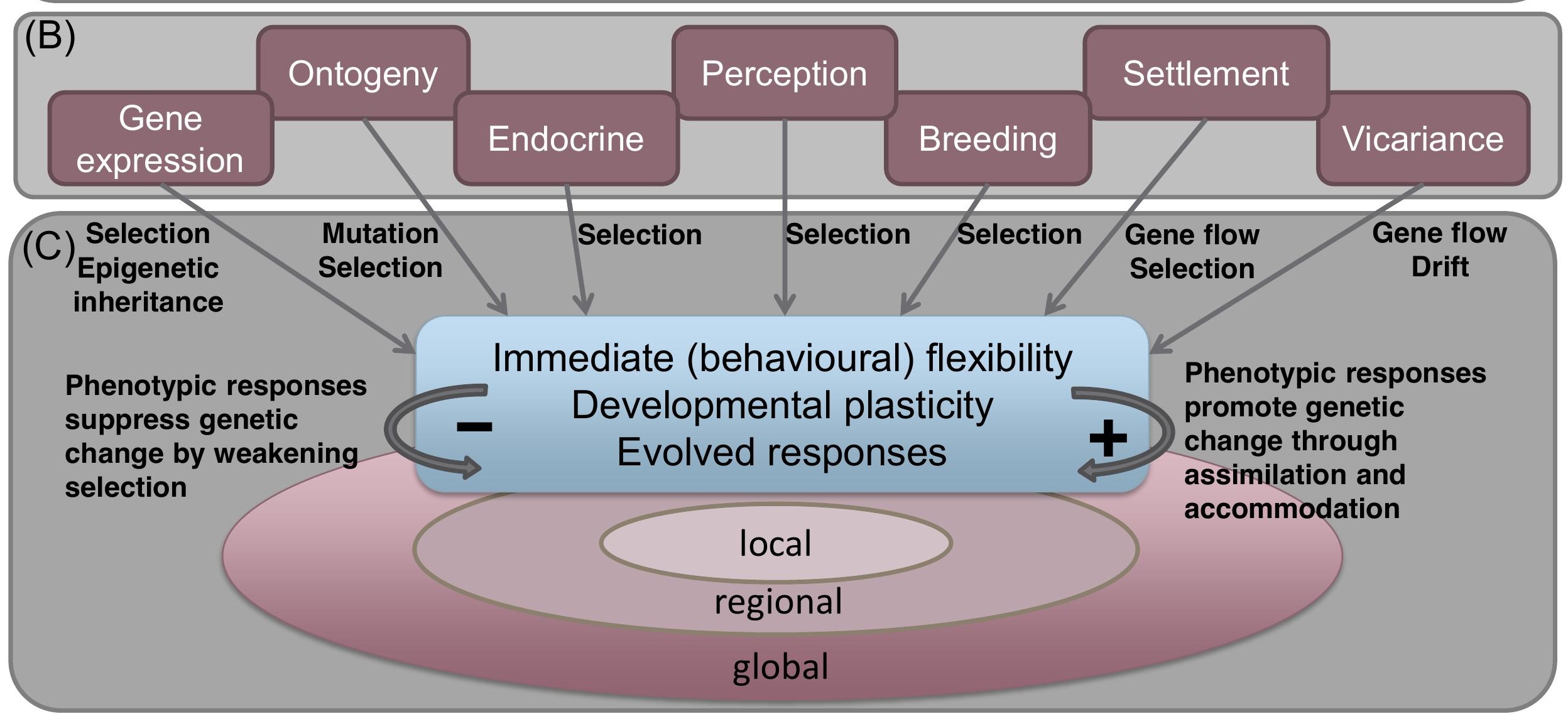




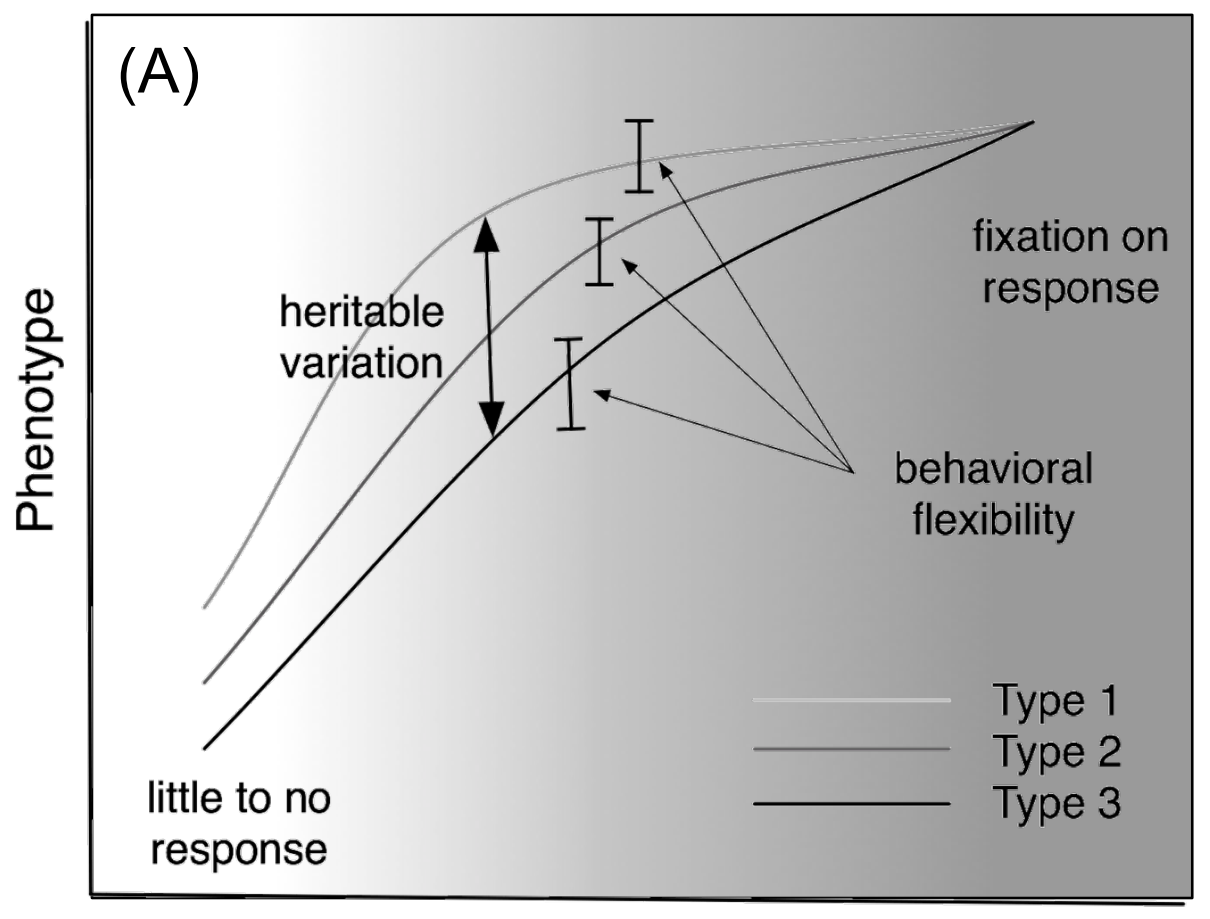

Stimulus (light or sound)

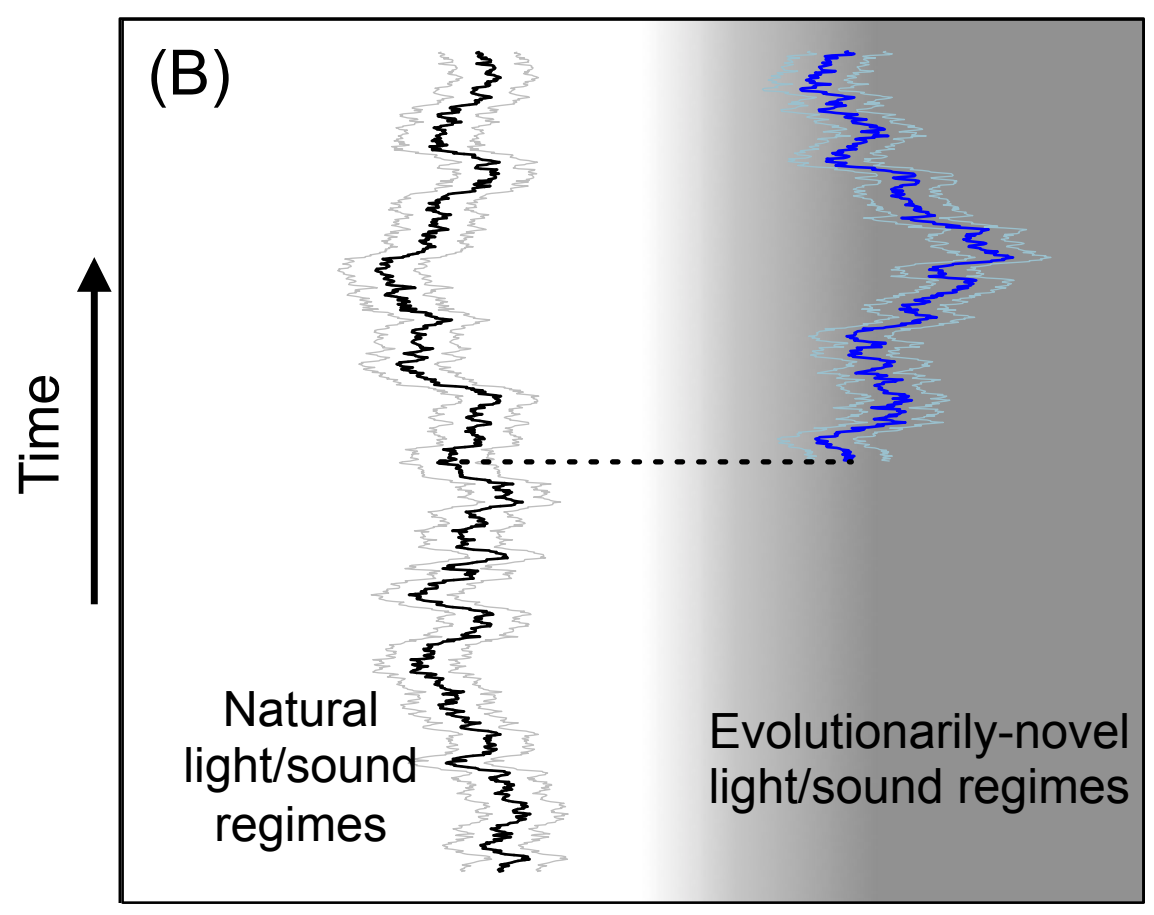

Phenotype trait values 